\title{
Detection by ELISA of low numbers of Shiga-like toxin- producing Escherichia coli in mixed cultures after growth in the presence of mitomycin $\mathrm{C}$
}

\author{
D. LAW, LEELA A. GANGULI, A. DONOHUE-ROLFE* and D. W. K. ACHESON*
}

Department of Microbiology, Hope Hospital, Eccles Old Road, Salford, Manchester M6 8HD and "Division of Geographic Medicine and Infectious Diseases, Box 41, New England Medical Center, 750 Washington Street, Boston, MA 02111, USA

\begin{abstract}
Summary. Techniques currently available to detect Shiga-like toxin (SLT)-producing Escherichia coli lack sensitivity or require specialised equipment and facilities, and in some cases detect only strains belonging to serotype O157. We have used an ELISA technique, capable of detecting both SLTI and SLTII with crude P1 glycoprotein from hydatid cysts, in combination with enhancement of toxin production by culture with mitomycin $\mathrm{C}$. Supernates of Tryptone Soya Broth cultures containing mitomycin C $200 \mathrm{ng} / \mathrm{ml}$ were tested for SLTII. For SLTI, cell lysates pre-treated with polymyxin B were tested. In tests with E. coli $\mathrm{O} 157: \mathrm{H} 7$ in mixed culture with $E$. coli strain $\mathrm{C} 600$ alone, or with $E$. coli $\mathrm{C} 600$, Proteus mirabilis and Enterococcus faecalis, SLTI could be detected when the proportion of toxigenic organisms represented $1 \%$ of the mixture, and SLTII when the proportion was $0.025 \%$. When faecal samples with added E. coli $\mathrm{O} 157: \mathrm{H} 7$ were examined in this system, SLTII-producing strains were detected when they comprised $<0.1 \%$ of the coliform population. This technique is a sensitive and specific assay for detecting low numbers of SLT-producing organisms in mixed culture such as occurs in cases of haemolytic uraemic syndrome and haemorrhagic colitis.
\end{abstract}

\section{Introduction}

Enteric infections complicated by haemorrhagic colitis (HC) or the haemolytic uraemic syndrome (HUS) are commonly associated with Escherichia coli strains that produce cytotoxins. ${ }^{1-4}$ These cytotoxins occur in two principal forms-Shiga-like toxin (SLT) I, which is almost identical to the toxin elaborated by Shigella dysenteriae type 1 , and SLTII which, although immunologically distinct from SLTI, shares approximately $60 \%$ amino-acid homology. ${ }^{4}$ The subunit structure, mechanism of action and biological activity (enterotoxicity, neurotoxicity and cytotoxicity) are similar for SLTI and II, ${ }^{5}$ and both toxins bind to globotriaosyl ceramide (Gb3) which may be an important receptor in vivo. ${ }^{6}$ In most strains of SLTproducing $E$. coli, the toxin genes are carried by

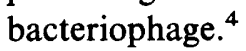

The laboratory diagnosis of infection with SLTproducing $E$. coli can be difficult. In many laboratories, diagnosis is made by faecal culture on sorbitolMacConkey agar to isolate strains of $E$. coli serotype O157 which are sorbitol non-fermenters, followed by agglutination with specific antisera. ${ }^{1}$ However, this technique may produce false positive results because

Received 14 Feb. 1991 ; accepted 8 May 1991. of isolation of non-toxigenic strains of E. coli $\mathrm{O} 157$ and $E$. hermanii. ${ }^{7}$ Of greater importance is the failure of this technique to detect sorbitol-fermenting SLTproducing strains of $E$. coli of serotypes other than O157, which are frequently implicated as causes of HC and HUS. ${ }^{1,8}$ A recent study in the UK showed that only $72 \%$ of infections with cytotoxin-producing $E$. coli were caused by strains belonging to serotype $0157 ;{ }^{8}$ thus $28 \%$ of strains would ferment sorbitol and would not be detected by this method.

Other techniques to detect SLTs are available. In laboratories with tissue-culture facilities, direct inoculation of filtered faecal suspensions on to susceptible cell lines, or examination of $E$. coli culture supernates or cell lysates can be performed. ${ }^{1}$ However, the specificity of any cytotoxic activity must be confirmed with appropriate neutralising antibodies. Detection of toxin genes with DNA probes, ${ }^{9-11}$ with or without the polymerase chain reaction (PCR), ${ }^{12,13}$ is an alternative approach.

ELISA techniques have also been developed for detection of Shiga-like toxin with monoclonal antibodies ${ }^{14}$ or Gb3 $3^{15,16}$ to bind toxin. Recently, P1 glycoprotein from hydatid cyst fluid, which contains the same terminal Gal $\alpha 1-4$ Gal disaccharide as Gb3, has been used to bind SLTI and II for both toxin purification ${ }^{17}$ and quantitation by ELISA. ${ }^{18}$

Toxin yields of SLTI and II can be markedly 
increased by incubation of bacterial cultures with mitomycin C. ${ }^{19}$ This technique has been utilised to allow purification of enough SLTII for biochemical characterisation. $^{20}$

A major problem in the diagnosis of SLT-producing $E$. coli in HUS and HC is that the numbers of toxinproducing organisms decreases as the disease progresses, ${ }^{21}$ such that the number of toxin-producing $E$. coli represents $<1 \%$ of the total faecal $E$. coli population. ${ }^{1,2,8}$ Therefore, tests aimed at detecting toxin-producing organisms must have adequate sensitivity and be as rapid as possible.

In this study we have used an ELISA, in combination with culture in the presence of mitomycin $\mathrm{C}$, to develop an easily applicable and sensitive assay for the detection of SLTI- and II-producing organisms.

\section{Materials and methods}

\section{Bacterial strains}

The following strains were used throughout the study. E. coli K-12 strain C600 was used as a non-SLT producing control. Strain $\mathrm{C} 600$ lysogenised with phage 933J or $933 \mathrm{~W}$ was used as a producer of either SLTI or SLTII, respectively, and E. coli O157:H7 strain 933, which produces both SLTI and II, was used as the toxin-producing strain. All were kindly provided by the late $\mathrm{Dr} \mathrm{H}$. Williams-Smith. A clinical isolate of E. coli $\mathrm{O} 157: \mathrm{H} 7$ producing SLTII only was used in some experiments.

A strain of Proteus mirabilis and a strain of Enterococcus faecalis isolated from a faecal sample were used in combination with E. coli $\mathrm{C} 600$ to simulate mixed faecal flora.

\section{Cultural conditions and preparation of mixed cultures}

Bacteria grown in Tryptone Soya Broth (TSB; Difco) overnight at $37^{\circ} \mathrm{C}$ were used to inoculate TSB or TSB containing mitomycin C (Sigma). Cultures were then incubated at $37^{\circ} \mathrm{C}$ for $18 \mathrm{~h}$ with shaking $(110 \mathrm{rpm})$. Initially, mitomycin $\mathrm{C}$ was added at a range of concentrations of $0-1000 \mathrm{ng} / \mathrm{ml}$ to determine the optimal concentration required for production of SLT by $E$. coli $\mathrm{O} 157: \mathrm{H} 7$ strain 933 .

Mixed cultures were prepared by inoculating $8 \mu \mathrm{l}$ of dilutions (25-10 000) of a culture of E. coli 0157:H7 strain 933 and an equal volume of a culture of $E$. coli strain $\mathrm{C} 600$ or an equal mixture of $E$. coli $\mathrm{C} 600, P$. mirabilis and Ent. faecalis into TSB. Viable counts $(\mathrm{cfu} / \mathrm{ml})$ were performed on CLED Agar (Lab M) on the culture used as the inoculum and on the mixture following overnight incubation.

\section{Preparation of faecal samples}

Faeces $(c .4 \mathrm{~g})$ from a patient with diarrhoea was suspended in $10 \mathrm{ml}$ of PBS and the cfu/g of faeces was determined on CLED agar. The remaining faecal sample was stored at $4^{\circ} \mathrm{C}$. Following the determination of the viable count, a freshly prepared suspension of the faecal sample was used to inoculate a series of broths containing mitomycin C $200 \mathrm{ng} / \mathrm{ml}$ with $c .10^{6}-$ $10^{7} \mathrm{cfu}$. Dilutions of the E. coli O157:H7 strain 933 were then added. Viable counts were performed on the faecal sample and the E. coli $\mathrm{O} 157: \mathrm{H} 7$ culture to determine the proportions of faecal: toxigenic organisms in the mixture. A broth inoculated with the faecal suspension alone served as a control. This procedure was repeated with two other faecal samples.

\section{Preparation of culture supernates and cell lysates}

After overnight incubation, the cultures were centrifuged for $10 \mathrm{~min}$ at $3000 \mathrm{~g}$. For SLTII, supernates were harvested and assayed by ELISA. For SLTI, cell pellets were resuspended in $300 \mu \mathrm{l}$ of polymyxin B (Sigma) $2 \mathrm{mg} / \mathrm{ml}$ in PBS, vortex mixed and incubated at $37^{\circ} \mathrm{C}$ for $15 \mathrm{~min}$. The lysate was centrifuged in a bench top microfuge for $2 \mathrm{~min}$ and the clear supernate was assayed by ELISA. Polymyxin lysis of cell pellets gave at least a five-fold increase in the yield of SLTI.

\section{ELISA}

SLTI and II were assayed by an ELISA technique as previously described. ${ }^{17}$ Briefly, ELISA plates (Nunc Immunoplates) were coated with crude hydatid cyst material ${ }^{17} 10 \mu \mathrm{g} / \mathrm{ml}$ in PBS, and then blocked with bovine serum albumin $1 \%$. Supernate or cell lysate preparations were added and bound toxin was detected with rabbit polyclonal antibodies raised against the two toxins separately. ${ }^{16}$ A goat anti-rabbit IgG conjugated to alkaline phosphatase (Sigma) followed by substrate (nitrophenol phosphate; Sigma) was used to detect bound polyclonal antibody. Absorbance was measured at $410 \mathrm{~nm}$. To quantify the amount of toxin in the preparation, Shiga toxin and SLTII, purified as described previously, ${ }^{16}$ were diluted in PBS and used as standards in the ELISA.

\section{Results}

Experiments to determine the concentration of mitomycin $\mathrm{C}$ for the maximal induction of toxin in $E$. coli $0157: \mathrm{H} 7$ strain 933 showed that $200 \mathrm{ng} / \mathrm{ml}$ was optimal (table I). This concentration was used in subsequent experiments.

The ELISA was able to detect $1.6 \mathrm{ng}$ of purified Shiga toxin (SLTI) and $1.6 \mathrm{ng}$ of SLTII per ml. It was confirmed that $E$. coli strain $\mathrm{C} 600(933 \mathrm{~J})$ produced SLTI only and E. coli C600 (933W) produced SLTII only. E. coli $\mathrm{O} 157: \mathrm{H} 7$ strain 933 produced both toxins. Comparison of cultures of these three strains grown with and without mitomycin C $200 \mathrm{ng} / \mathrm{ml}$ showed that toxin titres were markedly increased in all three strains by growth in the presence of mitomycin C (table II). 
Table I. Production of SLTI and II by $E$. coli O157:H7 strain 933 measured by ELISA after growth in TSB containing mitomycin C

\begin{tabular}{c|rr}
\hline $\begin{array}{c}\text { Mitomycin C } \\
\text { concentration } \\
(\mathrm{ng} / \mathrm{ml})\end{array}$ & Toxin detected $(\mathrm{ng} / \mathrm{ml})$ by ELISA \\
\cline { 2 - 3 } & SLTI & SLTII \\
\hline 0 & 10 & 160 \\
50 & 400 & 8000 \\
100 & 800 & 10000 \\
200 & 1600 & 32000 \\
400 & 900 & 20000 \\
800 & 160 & 8000 \\
1000 & 120 & 5000 \\
\hline
\end{tabular}

Table II. Effect of growth with mitomycin C on production of SLTI and II detected by ELISA in culture supernate (SLTII) and polymyxin-induced cell lysates (SLTI)

\begin{tabular}{lc|cc}
\hline \multirow{2}{*}{ Strain } & $\begin{array}{c}\text { Growth with } \\
\text { mitomycin C }\end{array}$ & \multicolumn{2}{|c}{ Titre in ELISA of } \\
\cline { 3 - 4 } & & SLTI & SLTII \\
\hline E. coli C600 (933J) & + & 400 & ND \\
& - & Neat & ND \\
E. coli C600 (933W) & + & ND & 32000 \\
& - & ND & 400 \\
E. coli $0157: \mathrm{H7}$ & + & 400 & 16000 \\
$(993)$ & - & Neat & 200 \\
& & &
\end{tabular}

ND, not detected.

When $E$. coli $\mathrm{O} 157: \mathrm{H} 7$ strain 933 was co-inoculated at different dilutions with a fixed number $\left(10^{7}\right)$ of $E$. coli $\mathrm{C} 600$ into broth containing mitomycin $\mathrm{C}$, it was possible to detect SLTI in cell lysates when the proportion of toxin-producing cells at inoculation was $0.5 \%$ (table III). However, detection of SLTII in supernates was possible when the proportion of strains was $0.0125-0.025 \%$ (table IV).
Similar results were obtained with a mixed culture of $P$. mirabilis, Ent. faecalis and $E$. coli strain C600 incubated with $E$. coli $\mathrm{O} 157: \mathrm{H} 7$ strain 933 (tables III and IV). Detection of SLTI in cell lysates was possible when the proportion of toxin producers was $0.5 \%$, and, for SLTII, positive reactions were found when the proportion of toxin producers was $0.0125-0.025 \%$ (tables III and IV). When the experiment was conducted in the absence of mitomycin C, SLTI was detected only in pure cultures and SLTII in cultures comprising $0.5 \%$ of toxin-producing organisms (tables III and IV).

When a different clinical isolate of E. coli $\mathrm{O} 157: \mathrm{H} 7$ which produced SLTI, was co-inoculated with the three-organisms mixture, SLTII production was also detectable when the proportion of the toxin-producer was as low as $0 \cdot 1 \%$.

With three different faecal samples seeded with $E$. coli O157:H7 strain 933, SLTII was detected when the proportion of toxigenic organisms was $<0.1 \%$ in all three samples and $<0.05 \%$ in one case. In each case, SLTII was not detected in any of the faecal samples inoculated into broth without the $E$. coli O157:H7 strain. These samples were not examined for SLTI production.

\section{Discussion}

Diagnosis of $E$. coli infections which are associated with $\mathrm{HC}$ or HUS requires a rapid, specific and sensitive laboratory test. Existing techniques, such as sorbitol MacConkey agar, lack specificity, others such as tissue culture cytotoxin tests lack speed or are not readily available, e.g., DNA probes and PCR. ELISAs to detect toxins have been developed with various techniques, and are able to detect very small (ng) quantities of either SLTI or SLTII. Thus, although less sensitive than tissue culture, ELISAs do offer

Table III. Detection of SLTI, determined by ELISA with cell lysates of $E$. coli O157:H7 strain 933 grown in TSB (with or without mitomycin C $200 \mathrm{ng} / \mathrm{ml}$ ) in variable proportions with either $E$. coli strain $\mathrm{C} 600$ or a mixture of E. coli $\mathrm{C} 600$, $P$. mirabilis and Ent. faecalis

\begin{tabular}{|c|c|c|c|}
\hline \multirow{2}{*}{$\begin{array}{l}\text { Percentage of } \\
\text { E. coli } \mathrm{O} 157: \mathrm{H} 7 \\
\quad \text { in mixture }\end{array}$} & \multicolumn{3}{|c|}{$\begin{array}{l}\text { ELISA Optical Density (A) at } 410 \mathrm{~nm} \text { (SD) of lysate after } \\
\text { culture with }\end{array}$} \\
\hline & $\begin{array}{l}\text { E. coli } \mathrm{C} 600+ \\
\text { mitomycin C }\end{array}$ & $\begin{array}{l}\text { mixture+ } \\
\text { mitomycin C }\end{array}$ & mixture only* \\
\hline 100 & $1 \cdot 67(0 \cdot 18)$ & $1 \cdot 35(0 \cdot 7)$ & 0.37 \\
\hline 10 & NT & NT & 0.08 \\
\hline 4 & $1.06(0 \cdot 2)$ & $0.71(0 \cdot 12)$ & 0.08 \\
\hline 2 & $0.69(0.15)$ & $0.22(0.03)$ & 0.06 \\
\hline 1 & $0.32(0.04)$ & $0.33(0.06)$ & 0.05 \\
\hline 0.5 & $0.43(0.10)$ & $0.14(0.02)$ & 0.06 \\
\hline 0.25 & $0 \cdot 10(0)$ & $0.06(0.01)$ & 0.05 \\
\hline Control & $0.06(0.01)$ & $0.05(0.02)$ & 0.05 \\
\hline
\end{tabular}

Results are expressed as mean $\mathrm{A}_{410}$ (SD) from four separate experiments each performed in duplicate wells.

NT, not tested.

* Mean of duplicate wells from a single experiment. 
Table IV. Detection of SLTII, determined by ELISA, in supernates of $E$. coli O157:H7 strain 933 grown in TSB (with or without mitomycin C $200 \mathrm{ng} / \mathrm{ml}$ ) in variable proportions with either $E$. coli strain $\mathrm{C} 600$ or a mixture of $E$. coli $\mathrm{C} 600$, P. mirabilis and Ent. faecalis

\begin{tabular}{|c|c|c|c|}
\hline \multirow{2}{*}{$\begin{array}{l}\text { Percentage of } \\
\text { E. coli O157: } \mathrm{H} 7 \\
\quad \text { in mixture }\end{array}$} & \multicolumn{3}{|c|}{$\begin{array}{l}\text { ELISA Optical Density (A) at } 410 \mathrm{~nm} \text { (SD) of supernate after } \\
\text { culture with }\end{array}$} \\
\hline & $\begin{array}{l}\text { E. coli } \mathrm{C} 600+ \\
\text { mitomycin C }\end{array}$ & $\underset{\text { mitomycin } \mathrm{C}}{\operatorname{mixture}+}$ & mixture only* \\
\hline 1 & $0.61(0.06)$ & $0.65(0.06)$ & 0.44 \\
\hline 0.5 & $0.61(0.18)$ & $0.54(0.12)$ & $0 \cdot 35$ \\
\hline $0 \cdot 2$ & $0.38(0.09)$ & $0.37(0 \cdot 10)$ & $0 \cdot 10$ \\
\hline $0 \cdot 1$ & $0.32(0.04)$ & $0.33(0.06)$ & 0.05 \\
\hline 0.05 & $0.25(0.02)$ & $0.23(0.06)$ & 0.06 \\
\hline 0.025 & $0.20(0.05)$ & $0.17(0.05)$ & 0.05 \\
\hline 0.0125 & $0.13(0.02)$ & $0.09(0.03)$ & 0.06 \\
\hline Control & $0.06(0.01)$ & $0.06(0.01)$ & 0.06 \\
\hline
\end{tabular}

Results are expressed as mean $\mathrm{A}_{\mathbf{4} 10}$ (SD) from five separate experiments each performed in duplicate wells.

* Mean of duplicate wells from a single experiment.

relative speed, greater availability and potential for automation.

The sensitivity of the current ELISA was $1.6 \mathrm{ng} / \mathrm{ml}$ for SLTI and II, which is comparable to the sensitivity of a previously described ELISA with Gb3 as the capture system. ${ }^{22}$ To increase the sensitivity of our assay, toxin yields of the organisms were increased by growth in broth containing mitomycin $\mathrm{C}$. This enhanced the yield of both SLTI and SLTII from $E$. coli $\mathrm{O} 157: \mathrm{H} 7$ strain $933>100$-fold compared with growth in cultures without mitomycin $\mathrm{C}$.

The mechanism whereby mitomycin $\mathrm{C}$ increases toxin yields is not fully understood but may be a consequence of bacteriophage induction (D. W. K. Acheson, unpublished observations). The increase in phage particles and hence viral gene copies brought about by mitomycin $\mathrm{C}$ suggests that this compound amplifies the number of toxin genes per bacterial cell and may increase the sensitivity of DNA probes for these toxins. The enhancement of toxin production by mitomycin $\mathrm{C}$ also has potential for other methods of detection of SLT-producting $E$. coli.

Currently we have no explanation for the marked differences in the level of SLTI and SLTII produced by $E$. coli $\mathrm{O} 157: \mathrm{H} 7$ strain 933 . The lower levels of SLTI prevented detection of small numbers of this organism, methods to improve the yields of SLTI are being evaluated.

When E. coli strain $\mathrm{C} 600$ alone or mixtures of $E$. coli C600, P. mirabilis and Ent. faecalis were co-inoculated with varying numbers of $E$. coli $\mathrm{O} 157: \mathrm{H} 7$ strain 933 and grown in broth containing mitomycin C, SLTI was detected when the proportion of the $E$. coli O157:H7 strain was $0.5-1 \%$ of the population. Detection of SLTII however was achieved when $E$. coli $\mathrm{O} 157: \mathrm{H} 7$ represented only $0.0125-0.025 \%$ of the total. In tests with faecal samples seeded with $E$. coli O157:H7 strain 933, SLTII was detected when the organism comprised $<0.1 \%$ of the aerobic flora. This may be important because several studies have shown that, in cases of HUS, the number of cytotoxinproducing organisms was $<1 \%{ }^{1,8,10}$ The system described in this study provides a simple means of diagnosing infection with SLT-producing $E$. coli even when the organisms are present in low numbers. The technique must now be evaluated with clinical samples from patients with $\mathrm{HC}$ or HUS. The technique is easily applicable in routine diagnostic laboratories without the need for expensive equipment or expertise. However, at the present time antibodies to SLT are not widely available. Commercial development of an SLT assay would be welcomed.

There is growing evidence that SLTII-producing $E$. coli are more important than SLTI-producing $E$. coli in the pathogenesis of HC and HUS. ${ }^{23,24}$ This may reflect the much higher yields of SLTII compared with SLTI, a greater intrinsic toxicity of SLTII compared with SLTI, ${ }^{23}$ or a greater prevalence of SLTIIproducing strains. A recent survey in the UK showed that $83 \%$ of $E$. coli strains from HC or HUS cases produced SLTII only, whereas $5.6 \%$ of strains produced SLTI only and $11.3 \%$ of strains produced both toxins. ${ }^{8}$ Therefore, an assay that is able to detect low numbers of SLTII-producing strains would be highly advantageous for diagnostic purposes.

DWKA gratefully acknowledge the support of The Wellcome Trust. This work was supported by Grant AI-20253 from the National Institute of Allergy and Infectious Disease. We thank Drs D. W. Denning and M. G. L. Keaney for helpful discussions. 


\section{References}

1. Karmali MA. Infection by verocytotoxin producing Escherichia coli. Clin Microbiol Rev 1989; 2: 15-38.

2. Riley LW. The epidemiologic, clinical, and microbiologic features of hemorrhagic colitis. Annu Rev Microbiol 1987; 41: $383-407$.

3. Milford DV, Taylor CM. New insights into the haemolytic uraemic syndromes. Arch Dis Child 1990; 65: 713-715

4. O'Brien AD, Holmes RK. Shiga and Shiga-like toxins. Microbiol Rev 1987; 51 : 206-220.

5. Strockbine NA, Marques LRM, Newland JW, Williams Smith $\mathrm{H}$, Holmes RK, O'Brien AD. Two toxin-converting phages from Escherichia coli O157:H7 strain 933 encode antigenically distinct toxins with similar biologic activities. Infect Immun 1986; 53: 135-140.

6. Mobassaleh M, Donohue-Rolfe A, Jacewicz M, Grand RJ, Keusch GT. Pathogenesis of Shigella diarrhea: evidence for a developmentally regulated glycolipid receptor for shigella toxin involved in the fluid secretory response of rabbit small intestine. $J$ Infect Dis 1988 ; 157: 1023-1031.

7. Lior H, Borczyk AA. False positive identification of Escherichia coli O157. Lancet 1987; 1: 333.

8. Kleanthous H, Smith HR, Scotland SM et al. Haemolytic uraemic syndromes in the British Isles, 1985-8: association with Verocytotoxin producing Escherichia coli. Part 2: microbiological aspects. Arch Dis Child 1990; 65: 722-727.

9. Bettelheim KA, Brown JE, Lolekha S, Echeverria P. Serotypes of Escherichia coli that hybridized with DNA probes for genes encoding Shiga-like toxin I, Shiga-like toxin II, and serogroup $\mathrm{O} 157$ enterohemorrhagic $E$. colifimbriae isolated from adults with diarrhea in Thailand. $J$ Clin Microbiol 1990; 28 : 293-295.

10. Scotland SM, Rowe B, Smith HR, Willshaw GA, Gross RJ. Vero cytotoxin-producing strains of Escherichia coli from children with haemolytic -uraemic syndrome and their detection by specific DNA probes. J Med Microbiol 1988; 25: $237-243$.

11. Newland JW, Neill RJ. DNA probes for Shiga-like toxin I and II and for toxin-converting bacteriophages. J Clin Microbiol $1988 ; 26$ : $1292-1297$.

12. Karch $\mathrm{H}$, Meyer $\mathrm{T}$. Single primer pair for amplifying segments of distinct Shiga-like-toxin genes by polymerase chain reaction. J Clin Microbiol 1989; 27: 2751-2757.

13. Pollard DR, Johnson WM, Lior H, Tyler SD, Rozee KR. Rapid and specific detection of verocytotoxin genes in Escherichia coli by the polymerase chain reaction. $J$ Clin Microbiol $1990 ; 28: 540-545$.

14. Downes F, Green JH, Greene K, Strockbine N, Wells JG, Wachsmuth IK. Development and evaluation of enzymelinked immunosorbent assays for detection of Shiga-like toxin I and Shiga-like toxin II. J Clin Microbiol 1989; 27: 1292-1297.

15. Ashkenazi S, Cleary TG. Rapid method to detect Shiga toxin and Shiga-like toxin I based on binding to globotriosyl ceramide (Gb3), their natural receptor. J Clin Microbiol 1989; 27 : 1145-1150.

16. Basta M, Karmali M, Lingwood C. Sensitive receptor-specified enzyme-linked immunosorbent assay for Escherichia coli verocytotoxin. J Clin Microbiol 1989; 27: 1617-1622.

17. Donohue-Rolfe A, Acheson DWK, Kane AV, Keusch GT. Purification of Shiga toxin and Shiga-like toxins I and II by receptor analog affinity chromatography with immobilized P1 glycoprotein and the production of cross-reactive monoclonal antibodies. Infect Immun 1989; 57 : 3888-3893.

18. Acheson DWK, Keusch GT, Lightowlers M, Donohue-Rolfe A. Enzyme-linked immunosorbent assay for Shiga toxin and Shiga-like toxin II using $P_{1}$ glycoprotein from hydatid cysts. J Infect Dis 1990; 161 : 134-137.

19. Head SC, Petric M, Richardson S, Roscoe M, Karmali MA. Purification and characterization of verocytotoxin 2. FEMS Microbiol Lett 1988; 51 : 211-216.

20. Acheson DWK, Kane AV, Keusch GT, Donohue-Rolfe A. High yield purification and subunit characterisation of Shiga-like toxin II. Interscience Conference on Antimicrobial Agents and Chemotherapy 1989; Abstract no. $901: 252$.

21. Tarr PI, Neill MA, Clausen CR, Watkins SL, Christie DL, Hickman RO. Escherichia coli O157:H7 and the hemolytic uremic syndrome: importance of early cultures in establishing the etiology. J Infect Dis 1990; 162: 553-556.

22. Ashkenazi S, Cleary TG. A method for detecting Shiga toxin and Shiga-like toxin-I in pure and mixed culture. $J \mathrm{Med}$ Microbiol 1990; 32: 255-261.

23. Wadolkowski EA, Sung LM, Burris JA, Samuel JE, O'Brien AD. Acute renal tubular necrosis and death of mice orally infected with Escherichia coli strains that produce Shigalike toxin type II. Infect Immun 1990; 58 : 3959-3965.

24. Tarr PI, Neill MA, Clausen CR, Newland JW, Neill RJ, Moseley SL. Genotypic variation in pathogenic Escherichia coli $\mathrm{O} 157: \mathrm{H} 7$ isolated from patients in Washington, 1984 87. J Infect Dis 1989; 159: 344-347. 